\title{
Expression of cellular retinoic acid-binding protein I and II (CRABP I and II) in embryonic mouse hearts treated with retinoic acid
}

\author{
Emilia Stachurska1, Agnieszka Loboda², Justyna Niderla-Bielińska33, Małgorzata Szperl ${ }^{4}$, \\ Michał Juszyński ${ }^{1}$, Alicja Jozkowicz², Jozef Dulak² and Anna Ratajska1 ${ }^{1}$
}

1Department of Pathological Anatomy, Medical University of Warsaw, Warszawa, Poland; 2Department of Medical Biotechnology, Faculty of Biochemistry, Biophysics and Biotechnology, Jagiellonian University, Kraków, Poland; ${ }^{3}$ Department of Histology and Embryology, Medical University of Warsaw, Warszawa, Poland; ${ }^{2}$ Department of Molecular Biology, Institute of Cardiology, Warszawa, Poland

Cellular retinoic acid binding proteins are considered to be involved in retinoic acid (RA) signaling pathways. Our aim was to compare the expression and localization of cellular retinoic acid binding proteins I and II (CRABP $I$ and II) in embryonic mouse hearts during normal development and after a single teratogenic dose of RA. Techniques such as real-time PCR, RT-PCR, Western blots and immunostaining were employed to examine hearts from embryos at 9-17 dpc. RA treatment at $8.5 \mathrm{dpc}$ affects production of CRABP I and II in the heart in the 48-h period. Changes in expression of mRNA for retinaldehyde dehydrogenase II (Raldh2), Crabp1 and Crabp2 genes also occur within the same time window (i.e. 10-11dpc) after RA treatment. In the embryonic control heart these proteins are localized in groups of cells within the outflow tract (OT), and the atrioventricular endocardial cushions. A gradient of labeling is observed with CRABP II but not for CRABP I along the myocardium of the looped heart at $11 \mathrm{dpc}$; this gradient is abolished in hearts treated with RA, whereas an increase of RALDH2 staining has been observed at $10 \mathrm{dpc}$ in RA-treated hearts. Some populations of endocardial endothelial cells were intensively stained with anti-CRABP II whereas CRABP I was negative in these structures. These results suggest that CRABP I and II are independently regulated during heart development, playing different roles in RA signaling, essential for early remodeling of the heart tube and alignment of the great arteries to their respective ventricles.

Keywords: CRABP I, CRABP II, retinoic acid, neural crest, embryonic mouse heart

Received: 29 April, 2010; revised: 21 December, 2010; accepted: 07 March, 2011; available on-line: 16 March, 2011

\section{INTRODUCTION}

Cellular retinoic acid binding proteins (CRABPs) are proteins of approximately $16-17 \mathrm{kDa}$, which bind retinoic acid (RA) with high affinity (Ong et al., 1994). They belong to the multigene family of intracellular lipid-binding proteins (ILBP) (see Bernlohr et al., 1997 for a review). To this day two types of these proteins have been characterized: CRABP I (Ong et al., 1994) and CRABP II (Giguére et al., 1990). Both proteins are present in the embryo as well as in the adult, and their expression is time- and tissue-specific (Dekker et al., 1994; Bucco et al.,
1996), therefore each of these proteins is likely to have an important physiological function.

Both CRABP I and II are present in the cytoplasmic compartment of various cells (Gaub et al., 1998) and CRABP II is also found in the nucleus (Delva et al., 1999). Due to this fact as well as their high affinity and specificity for RA (Dong et al., 1999) CRABPs are believed to messenger RA signaling in the cell. Both proteins might contribute significantly to RA metabolism, but their biological role has not been fully elucidated. The levels of CRABPs in the embryo undergo dramatic changes during development. Expression of CRABP II in murine embryo seems to be more widespread and at a lower level than that of CRABP I (Leonard et al., 1995), and each of these is expressed in a tissue- and organspecific manner (Dekker et al., 1994; Bucco et al., 1996) suggesting different functions.

It has been demonstrated that upon binding retinoic acid CRABP I participates in RA catabolism by producing its inactive metabolites (Boylan \& Gudas, 1992). Because of this CRABP I is thought to buffer the amount of free intercellular RA and alter its amount entering the nucleus (Maden et al., 1988; Perez-Castro et al., 1989). In this way CRABP I may prevent teratogenic effects of excessive RA levels on various tissues (Dingle et al., 1972) or may accumulate RA in the cells protecting them from possible hypovitaminosis A (Lampron et al., 1995). On the other hand, CRABP II might be involved in transporting RA to the nucleus and therefore take part in the activation of nuclear RA receptors and regulation of RAdependent genes (McCaffery \& Dräger, 2000; Ross et al., 2000; Zhelyaznik et al., 2003; Theodosiou et al., 2010).

Furthermore, promoters of both CRABP genes contain RA-response elements (RARE), being themselves targets for action of retinoic acid (Aström et al., 1991; Durand et al., 1992; Kleinjan et al., 1998). However, their regulation by RA seems to be tissue-specific (Aström et al., 1991; Leonard et al., 1995). For instance an exogenous teratogenic dose of RA causes an increase of mRNA level for CRABP II in various cell lines and tissues in vitro (Lyn \& Giguére, 1994; Williams et al., 2004), whereas mRNA for CRABP I remains unaffected (Lyn

e-mail: arataj@ib.amwaw.edu.pl

Abbreviations: BSA, bovine serum albumin; CNCCs, cardiac neural crest cells; CRABP, cellular retinoic acid-binding protein; dpc, days post coitus; ECs, endothelial cells; EECs, endocardial endothelial cells; NCCs, neural crest cells; OT, outflow tract; RA, retinoic acid; RALDH2, retinaldehyde dehydrogenase II; SHF, second heart field; TBS, Tris-buffered saline. 
\& Giguére, 1994). This may indicate that the two genes are regulated differently.

CRABPs are markers for neural crest cells (NCCs), their derivatives (Ruberte et al., 1990; Maden et al., 1991; Ilagan et al., 2006), and areas of intense morphogenetic processes in various embryonic tissues (Perez-Castro et al., 1989; Maden et al., 1991; Ruberte et al., 1992) that correspond to sites of endogenous RA synthesis (Berggren et al., 1999; 2001; Zhelyaznik et al., 2003). CRABPs are also localized in areas prone to RA-related teratogenesis (Kalter \& Warkany, 1961; Perez-Castro et al., 1989; Ruberte et al., 1990; Maden et al., 1990; Leonard et al., 1995).

It has been known for a long time, that RA, the active metabolite of vitamin $A$, is a potent, ubiquitous morphogene, crucial for prenatal vertebrate development and that it may also act as a teratogenic agent under conditions of its deficiency (Wilson et al., 1953) or excess (Lammer et al., 1985; Bouman et al., 1995; Yasui et al., 1995; 1997; 1999; Nakajima et al., 1996; 1997; Lee et al., 1998). Among tissues prone to RA-related teratogenesis is the developing heart (Wilson et al., 1953; Lammer et al., 1985; Rosa et al., 1986; Bouman et al., 1995; Yasui et al., 1995; 1997; 1999; Nakajima et al., 1996; 1997; Lee et al., 1998; Sinning, 1998). The subpopulation of cells belonging to the second heart field (SHF) is important for heart tube development. The second heart field requires precise levels of RA signaling in a narrow timewindow between $7.75 \mathrm{dpc}$ and $10.5 \mathrm{dpc}$ (Lavine et al., 2005; Sirbu et al., 2008). SHF and its proper addition to the developing heart tube are essential for correct alignment of the great arteries and normal development of the outflow tract (OT) (Yelbuz et al., 2002; Waldo et al., 2005). Both insufficiency and excess of local RA lead to serious cardiac defects, mostly within the OT region, for instance double outlet right ventricle (DORV), transposition of the great arteries (TGA), persistent truncus arteriosus (PTA), tetralogy of Fallot and others. RA signaling to SHF cells is mediated by fibroblast growth factor 8 (FGF8), whose proper amount is tightly controlled in SHF cells by RA (Ryckebush et al., 2008) and also by the cardiac neural crest cells (CNCCs) approaching the heart (Hutson et al., 2006). It has been demonstrated that the onset of RA-related teratogenesis within the heart occurs at around 8 to $10 \mathrm{dpc}$ (Wilson et al., 1953), which is when the NCCs are approaching and invading the heart (Hildreth et al., 2008). At that time (8 dpc) the cells of SHF are also added to the developing heart tube (Kelly et al., 2001).

We hypothesized that the expression and location of CRABP I and II in the developing heart may reflect the timeframe and areas of RA activity. Therefore, in this study we aimed to examine the expression and location of CRABP I and II proteins in the mouse embryonic heart during developmental stages from $9 \mathrm{dpc}$ to $17 \mathrm{dpc}$ and to compare these attributes with the developing hearts derived from RA-treated embryos. We propose that a single dose of RA administered at the time when the SHF cells contribute to the developing heart tube (Kelly et al., 2001) may alter the expression of CRABPs genes and location of CRABPs proteins. Additionally, one of our goals was to compare the expression of mRNAs for both proteins during normal heart development and at corresponding stages after RA treatment. To study the possible relationship between CRABP I, II and endogenous RA we analyzed the location of retinaldehyde dehydrogenase II (RALDH2) — the key RAsynthetic enzyme in hearts from control and RA-treated embryonic mice at the time of the assumed RA-mediated effect on the developing mouse heart (10-12 dpc).

\section{MATERIALS AND METHODS}

The study was performed according to the requirements of the 2nd Local Ethical Committee at the Medical University of Warsaw.

The study was performed on Balb/c mouse inbred strain and on F1 cross of B57BL/ 6 and CBA mouse inbred strains. Balb/c and F1 cross females were mated with males of their respective strain for two hours in the morning. Spontaneous ovulation and subsequent mating was indicated by the presence of vaginal plugs. Mice that had succesfully mated were housed separately for the purpose of collecting embryos. The time of joining the males with the females was recorded and was counted as day " 0 " for all obtained pregnancies. The remaining females were mated on the following days until impregnation.

At $8.5 \mathrm{dpc}$ half of the pregnant females were treated i.p. with all-trans-retinoic acid (Sigma-Aldrich, St. Louis, MO, USA) dissolved in $100 \mu \mathrm{l}$ of dimethylsulfoxide (Sigma-Aldrich), at a dose of $70 \mathrm{mg} / \mathrm{kg}$ body weight Embryos obtained from females that were not treated in any way (control embryos) served as comparison versus those exposed to a teratogenic dose of RA. In a pilot study performed on DMSO-treated control mice we obtained the same results with the RT-PCR method for CRABP $\mathrm{I}$ and II as on control non-treated mice. Three or more hearts or embryos were collected from every day of development for each procedure.

Hearts from control and RA-treated embryos were collected: 1. for RT-PCR and real-time PCR in RNasefree conditions, immediately frozen and kept at $-80^{\circ} \mathrm{C}$ for further analysis; 2. for tissue paraffin sections fixed in $4 \%$ buffered formaldehyde, rinsed with distilled water, dehydrated in increasing concentrations of ethanol and processed for paraffin embedding; 3. for Western blot in aseptic conditions, and immediately frozen and kept at $-20^{\circ} \mathrm{C}$ for further investigation. For Western blots with anti-CRABP I and II antibodies brains from embryos of all stages were also collected and kept frozen for further analysis. For Western blot with anti-RALDH2 antibodies the eye and the testis of adult mouse were collected as positive control tissue and kept frozen until used.

Reverse transcription-polymerase chain reaction and real-time PCR. Total cellular RNA was extracted by Qiazol extraction using a Tissue Lyser (Qiagen $\mathrm{GmbH}$, Hilden, Germany), according to the instructions provided by the producer. Synthesis of cDNA was performed on $0.5-1 \mu \mathrm{g}$ of total RNA with oligo-dT primers for $1 \mathrm{~h}$ at $42^{\circ} \mathrm{C}$ using RevertAid M-MuLV reverse transcriptase (Fermentas, Ontario, Canada) according to vendor's instruction.

PCR amplification with Taq polymerase was performed using the following protocol: 1 cycle $94^{\circ} \mathrm{C}$ for 2 min, followed by 35 cycles of $94^{\circ} \mathrm{C}$ for $45 \mathrm{~s}, 58^{\circ} \mathrm{C}$ for $45 \mathrm{~s}, 72^{\circ} \mathrm{C}$ for $1 \mathrm{~min}$.

Real-time PCR was carried out using a StepOnePlus apparatus (Applied Biosystem, Foster City, CA, USA) in a mixture containing $7.5 \mu \mathrm{l}$ SYBR Green PCR Master Mix (SYBR Green qPCR Kit, Sigma, Poznań, Poland), specific primers and $50 \mathrm{ng}$ of $\mathrm{cDNA}$ in a total volume of $15 \mu \mathrm{l}$ using the following cycling conditions: 1 cycle of $95^{\circ} \mathrm{C}$ for $15 \mathrm{~min}$, followed by 40 cycles of $95^{\circ} \mathrm{C}$ for $45 \mathrm{~s}, 58^{\circ} \mathrm{C}$ for $45 \mathrm{~s}$, and 1 cycle of $72^{\circ} \mathrm{C}$ for $45 \mathrm{~s}$. Primers specific for Crabp I gene (5'-TTC GCC GGT ACC 
TGG AAG ATG-3', 5'-CCC CCT CAA GAA GTG 'TCT GTG-3', for Crabp II gene (5'-CGT GGA TGG GAG ACC CTG TAA G-3' and 5'-CAG GCA GT'T CT'T GGA CCC GTA G-3'), and for Raldh2 gene (5'TCC AT'T CAC CAC TCT TGC CTC A-3' and 5'AGA AGG GAA GGA AGC CAG TGC 'T-3') were used. EF2 (elongation factor 2; 5'-GCG GTC AGC ACA ATG GCA TA-3' and 5'-GAC ATC ACC AAG GGT GTG CAG-3') was also amplified under the same conditions and was used as a housekeeping gene. PCR efficiency was determined for all three pairs of primers. All reactions were performed in duplicates. Controls containing SYBR Green PCR Master Mix and primers without sample cDNA emitted no fluorescence after 40 cycles. Relative quantification of gene expression was calculated based on the comparative $C_{\mathrm{T}}$ (threshold cycle value) method $\left(\Delta C_{\mathrm{T}}=C_{\mathrm{T}}\right.$ gene of interest $-C_{\mathrm{T}}$ housekeeping gene). Comparison of gene expression in different samples was performed based on the differences in $\Delta C_{\mathrm{T}}$ of individual samples $\left(\Delta \Delta C_{\mathrm{T}}\right)$. Results obtained from four different experiments were used to determine the level of mRNA for examined proteins. All data are presented as means \pm standard error (S.E.M.) and analyzed with Student's $t$-test. Differences were accepted as statistically significant at $P<0.05$.

Western blot. Embryonic hearts and embryonic brains, collected at different days of development, as well as adult eye and testis were homogenized in extraction buffer (Ripa; $10 \mathrm{mM}$ Tris/HCl; $0.15 \mathrm{M} \mathrm{NaCl}, 1 \%$ Triton $\mathrm{X}-100 ; 1 \%$ sodium deoxycholate; $0.1 \%$ SDS), containing protease inhibitors $(0.005 \%$ aprotinin and $0.01 \%$ phenylmethylsulfonyl fluoride (PMSF) at $+4{ }^{\circ} \mathrm{C}$.

Protein determination. One $\mu \mathrm{l}$ of embryonic heart extract or extraction buffer (blank test) and $9 \mu$ l of deionized water was placed in a flat-bottomed 96-well plate and $0.2 \mathrm{ml}$ of BCA protein assay reagent (Pierce, Rockford, Illinois, 61105 USA) was added to each well. The plate was incubated at $37^{\circ} \mathrm{C}$ for $30 \mathrm{~min}$. Protein concentration was determined spectrophotometrically at 550 nm (SLT Spectra Labinstruments, Crailsheim, Germany). For RALDH2 blots total protein in lysates was determined with BCATM Protein Assay (Thermo Scientific, Rockford, IL, USA). Protein transfer efficiency was determined by staining membranes with $1 \%$ Ponceau $\mathrm{S}$ in $1 \%$ acetic acid. After staining membranes were washed with $5 \%$ acetic acid, photographed, destained with tap water and blocked with $5 \%$ non-fat milk. Densitometric analysis was made with GelWorks $1 \mathrm{D}$ Intermediate (UVP, Upland, CA, USA).

Electrophoresis and Western blotting. Embryonic heart extracts $(10 \mu \mathrm{g}$ of protein) mixed in sample buffer with $\beta$-mercaptoethanol were separated by SDS/ polyacrylamide gel electrophoresis (SDS/PAGE; 12\% acrylamide) according to Laemmli (1970). Separated proteins were transferred onto PVDF membrane (Invitrogen, Carlsbad, CA, USA) by semi-dry blotting at $25 \mathrm{~V}$ for $30 \mathrm{~min}$, using a Trans-Blot SD apparatus (Bio-Rad Laboratories, Hercules, CA, USA). The membrane was incubated overnight with blocking buffer PBS (phosphate-buffered saline), $\mathrm{pH} 7.4$, containing $0.1 \%$ Tween and $2 \%$ non-fat milk. Then the membrane was incubated overnight with primary antibody. For CRABP I the primary antibody was obtained from Chemicon (Billerica, MA, USA; cat. No. MAB5484) or from Abcam (Cambridge, UK, cat. No. ab2816), whereas for CRABP II an antibody from Chemicon (cat. No. MAB5486) was used. Anti-RALDH2 antibody was a gift from Peter McCaffery and was used for immunohistochemical staining.
For Western blot anti-RALDH2 antibody was also obtained from Santa Cruz Biotechnology Inc. (Santa Cruz, CA, USA, ALDH1A2, cat. No. \# sc-22591). Goat antimouse immunoglobulins (DAKO A/S DK-2600 Glostrup, Denmark) served as the secondary antibody. Antibody binding was demonstrated by an amplified alkaline phosphatase detection system (Bio-Rad Laboratories, Hercules, CA, USA).

Due to the low level of CRABP I protein detected with the use of a standard Western blotting method (see above), chemiluminescence detection was additionally employed to assess the expression of this protein. After protein isolation (described above) and protein concentration measurement with the Quick Start Bradford Dye Reagent (Bio-Rad Laboratories) all samples were run on $12 \%$ SDS/polyacrylamide gel and transferred to PVDF membranes. Next membranes were immunoblotted with primary antibody against mouse CRABP I (Abcam, ab2816). All blots were then washed and incubated with an HRP-conjugated secondary antibody. The protein was then detected by enzyme-linked chemiluminescence with SuperSignal West Femto Maximum Sensitivity Substrate (Pierce).

Due to the low level of RALDH2 antigen in developing heart (the protein is present only in the proepicardium of $9 \mathrm{dpc}$ hearts and in the epicardial layer of mesothelial cells of 10-13 dpc hearts) the gel for standard Western blotting method was loaded with $25 \mu \mathrm{g}$ of protein instead of $10 \mu \mathrm{g}$.

Immunohistochemistry. Paraffin sections were serially cut and subsequently deparaffinized on a hot plate for $30 \mathrm{~min}$, immersed for $3 \times 10 \mathrm{~min}$ in xylene, and finally for $3 \times 10 \mathrm{~min}$ in $96 \%$ ethanol. After rinsing with PBS, the sections were treated in a microwave oven for $2 \times 5 \mathrm{~min}$ in $0.1 \mathrm{M}$ citrate buffer $(\mathrm{pH}$ 6.0) in order to retrieve antigenic determinants. After cooling the sections were incubated with mouse monoclonal antibodies: anti-CRABP I (diluted 1:500-1:1000 in TBS containing $1 \%$ BSA) (Chemicon; cat. No. MAB5484), or with antiCRABP II (diluted as above 1:1000-1:1500) (Chemicon; cat. No. MAB5486) overnight, at $+4{ }^{\circ} \mathrm{C}$, rinsed in PBS, and incubated with anti-mouse $\operatorname{IgG}$ peroxidase complex (Chemicon) for $30 \mathrm{~min}$. The color reaction was developed with 3,3'-diaminobenzidine tetrahydrochloride (DAB) (Sigma-Aldrich), the reaction was stopped in distilled water and sections were counterstained with hematoxylin.

For RALDH2 staining paraffin sections were deparaffinized, treated with citrate buffer as above, and incubated overnight with anti-RALDH2 antibodies $(1: 4000)$. Subsequently sections were rinsed with PBS, incubated with anti-rabbit IgG-biotin (DAKO) (1:300) for $30 \mathrm{~min}$, rinsed again with PBS, and incubated with streptavidinHRP complex (DAKO) $(1: 300)$. The color reaction was developed with DAB substrate.

To determine antibody specificity negative control stainings were performed on some sections without the addition of a primary antibody (Fig. S7, figures denoted $\mathrm{S}$ - see Supplementary Material at www.actabp.pl).

\section{RESULTS}

\section{Expression of mRNA for Crabp1, Crabp2 and Raldh2 genes}

In order to detect the expression of mRNAs for CRABP I and CRABP II RT-PCR technique was employed. In both control and retinoic acid-treated embry- 
os CRABP I and II mRNA was detectable from $9 \mathrm{dpc}$ to $17 \mathrm{dpc}$ (not shown).

The embryos were exposed to RA on $8.5 \mathrm{dpc}$, as this is the known moment of embryonic expression of Crabp1 and Crabp2 (Lyn \& Giguére, 1994) as well as based on the fact that two significant developmental events namely SHF addition to the heart tube and interaction between CNCCs and the SHF cells occur at that time, which are potentially affected by RA dosage (Nakajima et al., 1996; 1997; Yasui et al., 1995; 1997; 1999). Real-time PCR was employed to study quantitatively the expression levels of Crabp1, Crabp2 and Raldh2 genes. Assessment of these levels was begun shortly after RA treatment, at $9 \mathrm{dpc}$ (hearts from earlier stages were too small for tissue preparation), and lasted until $12 \mathrm{dpc}$ when the effect of RA on the levels of mRNA for all three genes seemed largely diminished.

We compared the basal level of expression of the examined genes at each day starting from 9 dpc. A strong decrease of mRNA levels for CRABP I and II was detected relative to the levels at $9 \mathrm{dpc}$ (Fig. 1). A decline in RALDH2 mRNA was observed at $10 \mathrm{dpc}$, but in the next days the expression increased almost to the level observed at 9 dpc (Fig. 1).

The effect of RA treatment, on the mRNA levels, was similar for all three studied genes (Crabp I, Crabp II and Raldh2) (Fig. 2). In samples obtained from 9 dpc RAtreated embryos significantly lower levels of mRNAs for all three genes were detected compared with their control counterparts. However, in hearts from embryos collected at $10 \mathrm{dpc}$ a reverse pattern could be observed, as mRNA production seemed to be greatly enhanced by the earlier RA treatment. At this developmental stage such difference in mRNA levels was much more apparent for both CRABP genes than for RALDH2. Similar, although slightly less pronounced up-regulation of all the genes studied, persisted in hearts of RA-treated embryos col- lected on the following day (11 dpc). On $12 \mathrm{dpc}$ mRNA expression for all three genes was similar in control and RA-treated hearts.

\section{Expression at the protein level}

The Western blot was employed to determine whether an effect of RA on Crabp1, Crabp2 and Raldh2 genes similar to that found for mRNA could also be detected at the protein level.

The bands obtained for CRABP I and II corresponded to the molecular mass of around $15-17 \mathrm{kDa}$ (Fig. 3). Despite the low levels of CRABP I protein, which remained barely detectable even when chemiluminescence detection was used, an increased amount of CRABP I protein could be observed in $9 \mathrm{dpc}$ heart following RAtreatment as compared to the control heart (Figs. 3 and 4A). This low amount of CRABP I protein in control hearts did not allow a comparison of the protein levels between control and RA-treated hearts at other time points studied. The level of CRABP II protein at $9 \mathrm{dpc}$ in the control heart was very low and high after RA treatment (Fig. 4B). It remained relatively high at $10 \mathrm{dpc}$ in both control and RA-treated hearts (as compared to its level in $9 \mathrm{dpc}$ control heart), and declined thereafter (Fig. 4B). The only distinctive response to RA treatment was detected at $9 \mathrm{dpc}$ in the levels of both CRABP I and II proteins suggesting similar regulation of both proteins by RA.

The expression of RALDH2 protein seemed not to be changed by RA treatment at 9-12 dpc (Fig. 4C) compared to control hearts.

Despite the obvious initial effect of RA treatment, the results obtained for later days of development did not suggest any further major changes in the level any of the proteins both in the course of normal heart development or following RA treatment. Therefore we ceased to study the levels of expression of all three proteins after 12 dpc.
A)

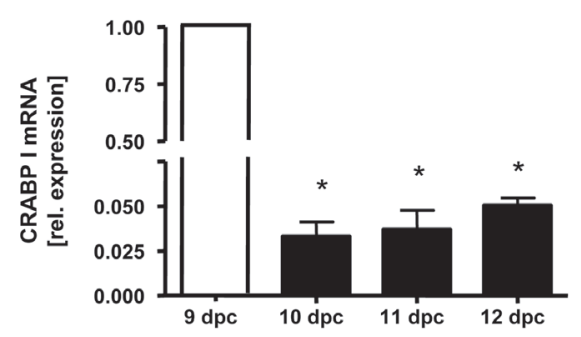

B)

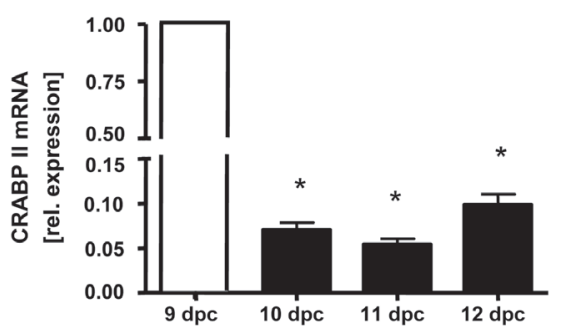

C)

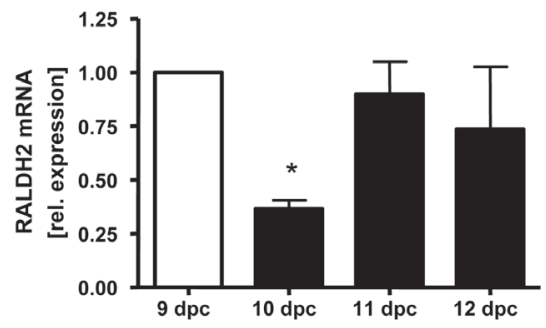

Figure 1. Real-time PCR for CRABP I (A), CRABP II (B) and RALDH2 (C) in control heart extracts from 9 dpc through 12 dpc Temporal dynamics of mRNA expression was normalized to the level on $9 \mathrm{dpc}$. Each column represents the mean \pm S.E.M. of four independent experiments run in duplicate. Values marked with a star vary significantly $(P<0.05)$ from the level on $9 \mathrm{dpc}$. 

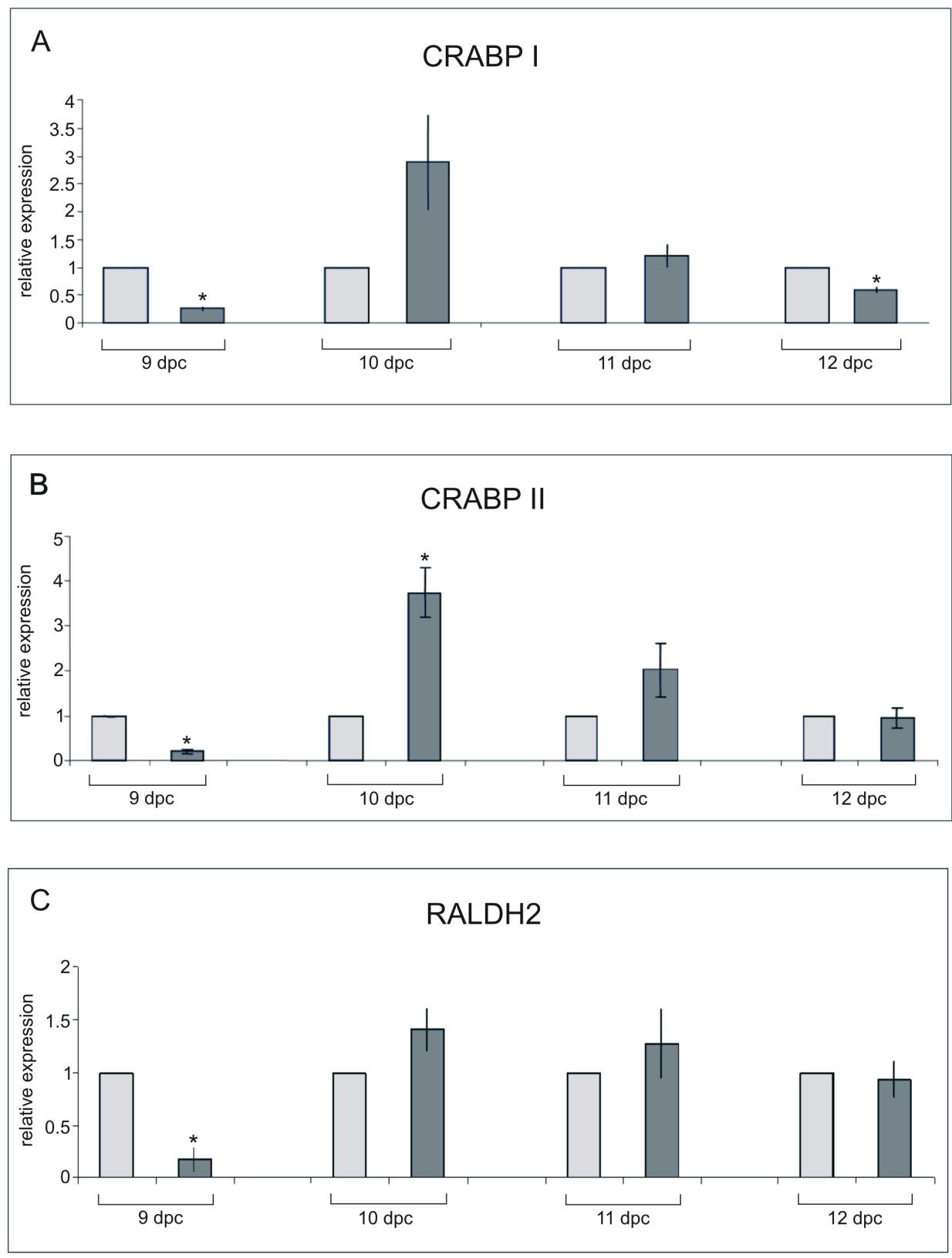

control hearts

RA-treated hearts

Figure 2. Real-time PCR for CRABP I (A), CRABP II (B) and RALDH2 (C) in control and RA-treated heart extracts from 9 dpc through 12 dpc

Comparison of mRNA levels for control and RA-treated hearts at each studied time point. Each column represents the mean \pm S.E.M. of four independent experiments run in duplicate and normalized to EF2 expression. At each time point, the value in control hearts is set as 1. For each time-point value in RA-treated hearts marked with a star varies significantly $(P<0.05)$ from its control counterpart.

\section{Localization of CRABP I, CRABP II and RALDH2 proteins}

To compare the localization of CRABP I and II proteins in both control and RA-treated hearts immunohistochemistry was used. Although quantitative studies showed only a short-term response to RA treatment at both mRNA and protein levels, an immunohistochemical study was carried out until the last day of pregnancy (17 $\mathrm{dpc}$ ) in order to determine whether a single teratogenic dose of RA induces any persistent spatial changes in the expression of CRABP I and II within specific cardiac structures.
At all the stages studied (Figs. S1-S6, and not shown), immunolabeling for CRABP I and II was detected within embryonic hearts. Both proteins were also present in hearts of RA-treated embryos. These results were validated with the use of negative controls (sections stained without the addition of a primary antibody) (Fig. S7) to eliminate false positives.

At the earliest stages, embryonic hearts exhibited fairly homogenous staining of different areas of the myocardium, which sometimes varied in intensity between CRABP I and II (10 dpc, Fig. S1, a and c, b and d; 12 dpc, Fig. S3, b and f, d and h). The only notable exception from this homogenous staining occurred at 


\section{CRABP I}

A

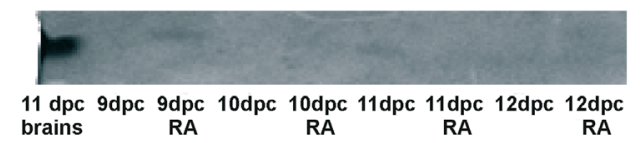

CRABP II

B

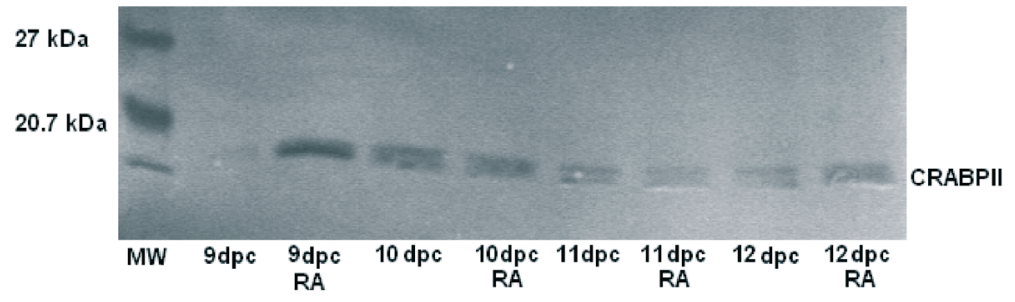

RALDH2

C

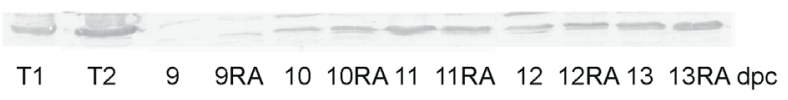

Figure 3. Western blot analysis of CRABP I (A), CRABP II (B) and RALDH2 (C) expression between 9 and $12 \mathrm{dpc}$ in control and RA-treated heart extracts.

The bands detected with anti-CRABP | (Abcam, ab2816) and anti-CRABP || (Chemicon, MAB5486) antibodies correspond to molecular mass of about $15-17 \mathrm{kDa}$, confirming antibody specificity. The band of $55 \mathrm{kDa}$ corresponds to RALDH2 protein (C). For CRABP I detection control tissue (brain) was loaded in the first lane. For RALDH2 detection control tissue consisted of mouse testis homogenate loaded in the first lane at $25 \mu \mathrm{g}$ (T1) and in the second lane at $50 \mu \mathrm{g}(\mathrm{T} 2)$.

$11 \mathrm{dpc}$ in control hearts, in which CRABP II location exhibited a gradient of staining intensity along the myocardium (Fig. S2d, e), being the strongest in the OT and atria. By contrast, the staining for CRABP I was evenly distributed within the ventricle, the atrium and the OT (Fig. S2a, b), and no such labeling gradient could be detected in RA-treated hearts stained for CRABP I or II (Fig. S2c, f). Besides this distinctive staining pattern in the myocardium, it is also worth noting that at 12 dpc after RA treatment the staining for anti-CRABP I exhibited a patchy pattern in aggregations of cells distributed evenly within the compact layer of the ventricles, ventricular trabeculae, the atrial myocardium, and the scattered cells of the endocardial cushions (Fig. S3c and $\mathrm{d}$ ). Higher magnification photographs revealed that this labeling was mostly located in the cytoplasm of the cells (Fig. S3, inset in d). Such labeling pattern resembling patches or dots could also be detected on some of the following days of development both in control (not shown) and RA-treated (Fig. S4c, d) hearts.

Additionally, a strong staining of endocardial endothelial cells (EECs) for CRABP II could be observed within the ventricles (Fig. S3b, f) and the atria (not shown) at $12 \mathrm{dpc}$ as well as in EECs of the OT cushions, and the developing semilunar valves, great arteries (Fig. S4e, f, g, Fig. S5f, g) and atria (Fig. S5h) at 13-14 dpc. Moreover, the mesenchymal cap of the forming interatrial septum exhibited staining for CRABP II at 11 (not shown) and 12 dpc (Fig. S3e, white arrow).

On the following days of heart development (13, 14 $\mathrm{dpc}$ ) homogenous labeling for CRABP I and II was de- tected in the ventricles, atria and the great arteries of control hearts (Fig. S4a, b, e, f) and hearts from RA-treated embryos (Fig. S4c, d, g, h; Fig. S5a, b, e, f) except for 14 dpc when the walls of great arteries exhibited significantly diminished staining (Fig. S5a, b, e, f, g). Additionally, at $13 \mathrm{dpc}$ and $14 \mathrm{dpc}$ in both control and RA-treated hearts, some of the mesenchymal cells of the OT cushions (Fig. S4a, $\mathrm{b}, \mathrm{e}, \mathrm{f})$ and the forming aortopulmonary septum (Fig. S5c, e, f, g) were labeled for CRABP I and II. The number of CRABP I and II positive cells in the OT cushion was, however, diminished in RAtreated hearts. As shown in insets in Fig. S4f and Fig. S5g the color reaction in these cells was mainly restricted to the cytoplasmic compartment.

At later stages of development $(15-17 \mathrm{dpc})$ in control hearts as well as those from RA-treated embryos the staining for CRABP I and II was evenly distributed within the myocardium except for the wall of the great vessels and the semilunar valves which showed no staining for either protein (not shown). At these stages of development staining for CRABP I and II was detected in the mesenchymal cells of the aorto-pulmonary septum (not shown) in hearts from control and RA-treated embryos. Labeling for both proteins was also present in the mesenchyme of the atrioventricular valves, localized close to the surface adjacent to the ventricular lumen in the control hearts. Similar staining for CRABP I and II could be observed in the mesenchyme of the atrioventricular valves following RA administration.

Throughout the stages studied the epicardium remained weakly stained for both CRABP I and II in control and RA-treated hearts. Interestingly in 13-dpc hearts the mesenchymal tissue underneath the epicardial layer exhibited positive staining for CRABP I in RA-treated hearts (Fig. S4d).

Besides the heart, color reaction was also observed in other developing tissues of the studied embryos, most notably in the neural epithelium and neural ganglia, gut mesenchyme, somites, limb mesenchyme, mesonephros, gonads and tail mesenchyme, which is in accordance with previous studies (Perez-Castro et al., 1989; Maden et al., 1991; Ruberte et al., 1991; 1992; Kleinjan et al., 1997). Staining for CRABP II was absent from the developing hepatic, osseous and cartilaginous tissue at all time points of the study.

Additionally, immunohistochemical staining for retinaldehyde dehydrogenase II (RALDH2) was performed in 10-12 dpc hearts. This technique was employed to determine areas of endogenous RA synthesis within the control and RA-treated hearts at these early stages of development, corresponding to the stages when RAmediated change of $\mathrm{mRNA}$ and protein levels for Crabp 1 and $\mathrm{Crabp} 2$ genes was detected. RALDH2 was detected 


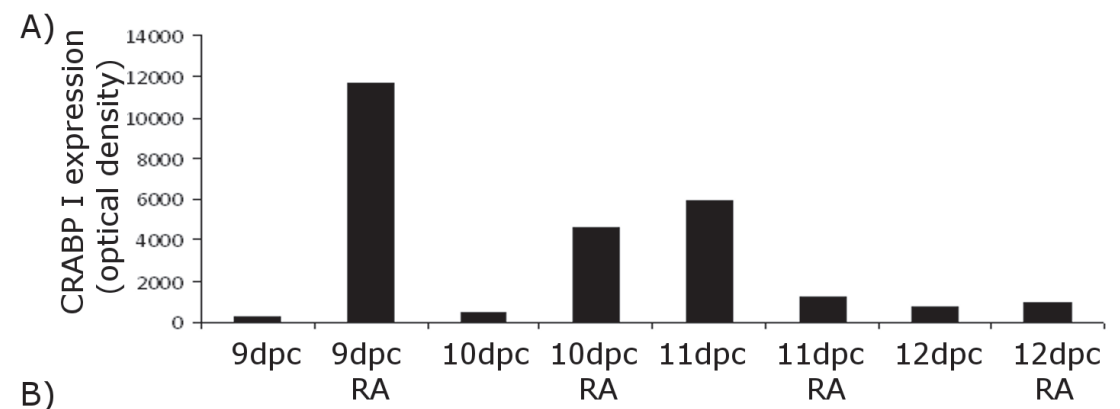

B)
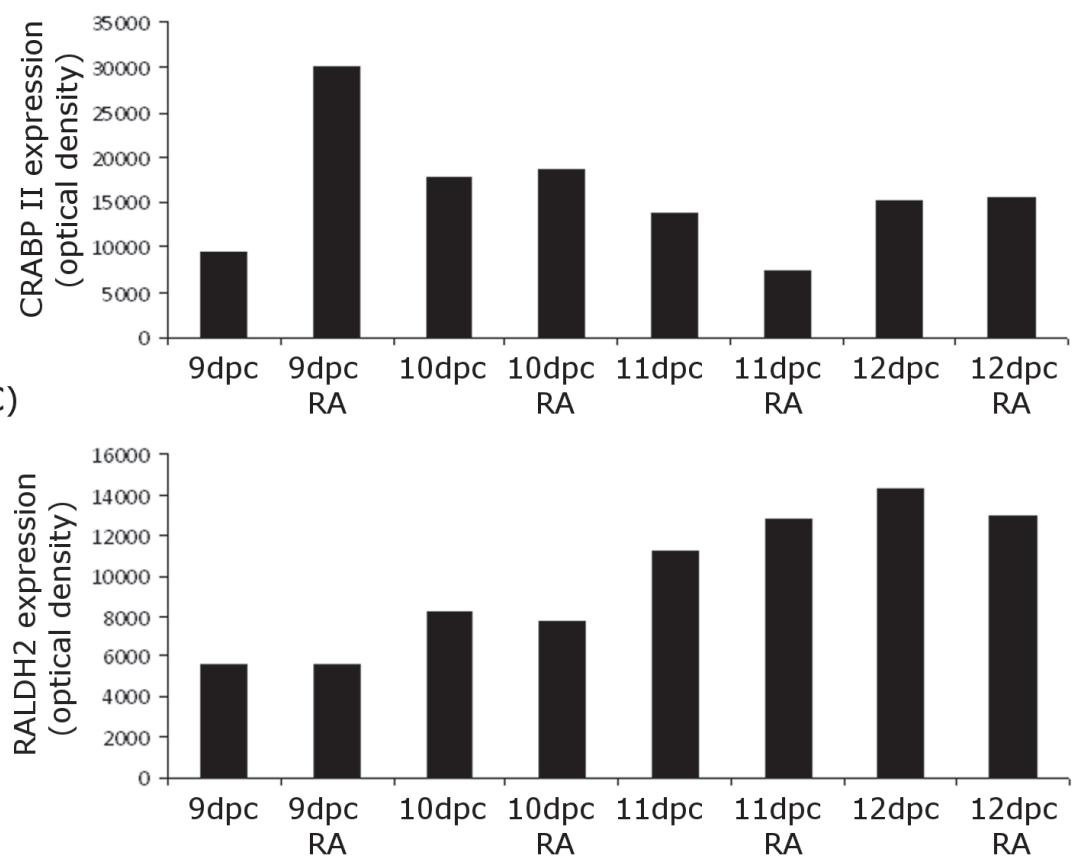

Figure 4. Optical density of Western blot for CRABP I (A), CRAPB II (B) and RALDH2 (C) protein bands

Ponceau S optical density was used as a correction factor for quantification. in relation to this organ. While some authors describe cardiac expression of these proteins, albeit at low levels as compared to other embryonic structures (Perez-Castro et al., 1989; Ruberthe et al., 1991; 1992), others failed to detect expression of these proteins in this developing organ (Kleinjan et al., 1997). Maden (1994) demonstrated CRABP II in the heart whereas CRABP I was not detected. These inconsistencies may be due to sensitivity of particular methods used in those studies.

Therefore in the present study we focused specifically on embryonic mouse heart, aiming to describe the dynamics of CRABPs expression in this organ at a critical period of its development. We also wanted to study the expression of RALDH2 the major RA-synthesizing enzyme in the heart, and the influence of exogenous RA treatment on RALDH2 protein and mRNA expression.

In this study we have shown that CRABP I and II proteins and their genes are expressed in embryonic mouse hearts at 9-17 dpc. We have demonstrated that:

1. The level of mRNA for CRABP I and II varies among the developmental stages of normal hearts and hearts from embryos treated with a single exogenous dose of RA.

2. As compared to control in the forming epicardium of 10, 11 and 12-dpc hearts (Fig. S6a-f). Additionally, this enzyme was present in some subepicardial cells penetrating towards the myocardium of 12-dpc hearts (not shown). These scattered cells are probably derived from the epicardial layer. In the RA-treated hearts from 10 and $11 \mathrm{dpc}$ embryos, RALDH2 staining of the epicardial tissue was markedly reduced (Fig. S6d, e) and at $10 \mathrm{dpc}$ it was also present in the myocardium, most notably in the region of the OT (Fig. S6d). Exceptionally strong RALDH2 staining was also observed in the surrounding extracardiac tissues (Fig. S6d, white arrow). Additionally, RALDH2 labeling was detected in proepicardial vesicles of control (Fig. S6, b) and RA-treated (inset in Fig. S6e) 9, 10 and 11-dpc hearts and in the forming blood islands of RA-treated, 12-dpc heart (Fig. S6f).

\section{DISCUSSION}

Although embryonic expression of CRABP I and II in the mouse has been described by several research groups (Ruberte et al., 1991; 1992; Lyn \& Giguére, 1994; Leonard et al., 1995), the presence of these proteins in the developing heart has not been given much attention. The results of studies aimed to detect embryonic expression of CRABP proteins seem to be somewhat contradictory samples, the level of mRNA for both CRABP I and II after RA treatment decreased at $9 \mathrm{dpc}$, and increased at $10 \mathrm{dpc}$. The same tendency was observed for mRNA of RALDH2.

3. RA treatment increased the expression of CRABP $\mathrm{I}$ and II protein in the heart within the first $24 \mathrm{~h}$ following treatment, with a subsequent decrease to a level found in control embryos. RA did not cause any variation in RALDH2 protein level within the first $24 \mathrm{~h}$ after treatment.

4. A staining "gradient" of CRABP II was observed in the arterial and venous poles of 11-dpc hearts, which may reflect the fact that RA mediates a developmental signal for these areas at that time. It is also possible that it is connected with the invasion of these structures by CNCCs. Both CRABP proteins were expressed in some cells within the OT. At the cellular level CRABP II was found transiently in some cells which remained negative for CRABP I throughout the study, for instance the endocardial endothelial cells.

The variation of mRNA levels for CRABP I and II within the $48 \mathrm{~h}$ after RA treatment as compared to control hearts suggests that this single dose of RA exerts its effect on the expression of both genes. A similar tendency was observed for the Raldh2 gene. The increased level of CRABP I and II protein in embryonic hearts 
within the first $24 \mathrm{~h}$ after RA treatment suggests that at the protein level CRABP I and II are also subject to RA regulation. This effect may be caused by an immediate up-regulation of mRNA for CRABP I and II, within a few hours after RA treatment, which would be consistent with previous observations on up-regulation of their genes in various cellular models in vitro (Boylan \& Gudas, 1992; Lyn \& Giguére, 1994; Williams et al., 2004). After studying the effect of RA treatment on the expression of various neural crest genes, Williams et al. (2004) classified Crabp II into a group of genes characterized by an immediate alteration of their mRNA levels in response to RA. Such reaction to RA occurred mostly within $6 \mathrm{~h}$ after treatment, and ceased after 12-24 h. In our study both CRABP I and II mRNAs were downregulated after $12 \mathrm{~h}$ following $\mathrm{RA}$ administration, that is at $9 \mathrm{dpc}$. In relation to these results, the increased protein level in 9-dpc RA-treated hearts observed in our study could be due to immediate gene upregulation by RA. In this scenario, an increased level of CRABP I and II protein could be observed even at $9 \mathrm{dpc}$, that is $12 \mathrm{~h}$ after RA dosage, when mRNA for these genes, initially up-regulated directly after RA dosage, had already been degraded. In addition a down-regulation of $\mathrm{mRNA}$ for CRABP I and II could be a result of negative feedback regulation of these genes by their products, that is by an excess of CRABP I and II proteins. At this time point (9 dpc) CNCCs, which are considered to be the major source of CRABP proteins in the developing organs, are not yet present in the heart (Hildreth et al., 2008), therefore the abundance of CRABP I and II proteins following RA treatment is likely the result of RA-induced ectopic expression. Subsequent upregulation of mRNA for CRABP I and II proteins at $10 \mathrm{dpc}$ may indicate that a single dose of RA given at $8.5 \mathrm{dpc}$ may also exert a further, delayed effect on their expression. We presume that this secondary upregulation may become more complex, not solely dependent on RA action, but involving other regulatory factors, for instance a diminished amount of gene end-products.

It is worth noting that specific molecular factors involved in RA-driven regulation of Crabp1 and Crabp2 genes are not yet fully determined. A study by Wang et al. (2004) points to a likely role of BAF180 of a chromatin remodeling complex PBAF in coactivation of Crabp2 gene presumably as a cofactor of nuclear RA receptors such as RXRa. Ablation of BAF180 causes cardiac defects characteristic for disrupted RA signaling pathway (Kastner et al., 1994; Sucov et al., 1994) such as hypoplastic ventricular myocardium and VSD (Wang et al., 2004). BAF180 has also been characterized as a factor indispensable for Crabp2 response to RA and this protein has been evidenced to bind directly to Crabp 2 promoter region (Wang et al., 2004). An effect of BAF180 ablation on the level of Crabp2 gene expression has also been described. It seems that BAF180 ablation and thus disruption of RA signaling pathway may cause either an increase or down-regulation (Wang et al., 2004) of expression of this gene. Such discrepancies may be explained by the different effect of RA signaling on particular genes based on specific localization in the embryonic heart, as the effect of RA is thought to be highly cell- and tissue-specific, and may be different for the same gene depending on the site of its expression (Wang et al., 2004, and references therein).

The fluctuations in the levels of mRNA and protein for CRABP I and II are the highest during the first $72 \mathrm{~h}$ following RA treatment. It is known that at this stage of cardiac development, CNCCs reach the heart (Poelmann \& Gittenberger-de Groot, 1999; Jiang et al., 2000; Hildreth et al., 2008) and the OT undergoes marked differentiation during which SHF cells are added to the developing OT and the proper alignment of the great arteries with their respective ventricles occurs (Kelly et al., 2001; Mjaatvedt et al., 2001; Yelbuz et al., 2002; Waldo et al., 2005; Buckingham et al., 2005; Rochais et al., 2009). At this time a "staining gradient" with anti-CRABP II was observed. This staining gradient for CRABP II, a marker of NCCs, was detected in the OT and the venous pole of 11-dpc control hearts. Firstly, such localization of staining may mark the cardiac areas populated by the NCCs, as both CRABP I and II are known to be molecular markers of these cells (Williams et al., 2004; Ilagan et al., 2006). This gradient, however, was not observed with anti-CRABP I antibodies, which may indicate that these two proteins are controlled differently. Additionally, this staining pattern may also indicate the sites of developmental action of RA signaling since CRABP II is though to transduce the RA signal (McCaffery \& Dräger, 2000; Ross et al., 2000; Zhelyaznik et al., 2003). These areas seem to converge with the fields of RA action within the heart which have been characterized by Moss et al. (1998), where both synthesis (sinus venosus, atria) and response to RA (sinus venosus, atria, and conotruncal area) is known to occur. SHF cells are themselves extremely sensitive to RA action during normal heart development, which has been demonstrated in mammals and other vertebrates (Collop et al., 2006; Vermot et al., 2006; Ryckebusch et al., 2008, Sirbu et al., 2008; Waxman et al., 2008; Rochais et al., 2009). Thus an excess of RA in our model causes heart malformations in the area where derivatives of the SHF are located and NCC cells accumulate (OT). Excessive RA signaling is known to disturb correct migration of the NCCs (Moss et al., 1998; Niederreither et al., 1999) and perturbs signaling between NCCs and SHF cells via action on Fgf8 (Hutson et al., 2006; Ilagan et al., 2006; Park et al., 2006). Fgf2 and Fgf9 are two other retinoid-induced growth factors which regulate heart development (Lin et al., 2010). It is interesting whether CRABP II participates in RA-dependent control of SHF and NCC cellular populations contributing to the arterial and the venous pole of the heart at that time. In that case CRABP II could be involved in sustaining locally-specific levels of RA signaling in these areas, which could be different from the levels of this signal in the ventricular compartment of the heart tube, based on the distinct origin of SHF and the NCCs. Exogenous, teratogenic doses of RA could affect this highly specific signaling and the expression of CRABP II as its component suppressing its gradient as seen at $11 \mathrm{dpc}$. Ectopic expression of RALDH2 in the outflow portion of the heart at $10 \mathrm{dpc}$ could also point to a role of excess RA in disrupting the normal pattern of endogenous RA signaling.

However, the putative participation of CRABP II in mediating RA signal for the developing heart requires confirmation with more detailed studies. The question whether suppresion of CRABP II staining gradient following RA treatment represents diminished contribution of the NCCs to the venous and arterial pole of the heart also remains open, as more molecular markers of the NCCs, preferably those not regulated by RA, would have to be used in order to resolve it.

At the intracellular level both proteins (CRABP I and II) were mostly located in the cytoplasmic compartments 
of cardiac myocytes and other cell types at these stages of development.

Interestingly, groups of cells in the OT cushions and the atrioventricular cushions at 11-13 dpc expressed both proteins and the number of these cells diminished after RA treatment. Also the labeling intensity between CRABP I and CRABP II in these groups of cells varied. This would be consistent with previous studies describing embryonic contribution of NCCs to specific cardiac structures (Hildreth et al., 2008), as well as reports claiming that such contribution can be diminished by RA treatment (Maden et al., 1996; Hoover et al., 2008). However, as stated above it is not clear whether such diminished staining can be directly identified with a lower contribution of the NCCs.

At 13-14 dpc a strong, distinct staining for CRABP II was also detected in the endocardial endothelial cells (EECs) of the OT, in the EECs of the right ventricular infundibulum, atria, and the forming semilunar valves in both control and RA-treated hearts. In contrast, CRABP I was absent from the EECs, suggesting that the roles played by both proteins in RA metabolism in various structures of the developing heart are different. Such a strong labeling for CRABP II might be explained by its upregulation by endogenous RA, as, according to the literature, the RA signal for cardiomyocyte development may come from the epicardium as well as from the endocardium (Kang \& Sucov, 2005). The developmental signal for nonmyogenic structures of the heart, such as the aorta and pulmonary arteries, semilunar valves and atrioventricular valves, which have been classified into one of cardiac "fields" of RA morphogenetic action (Moss et al., 1998), may be derived from the endocardium, initiated by an RA-synthesizing enzyme other than RALDH2 (as suggested in: Moss et al., 1998) and mediated specifically by CRABP II. On the other hand, RA signaling for the atrial and ventricular myocardium seems to be generated in the epicardium by RALDH2 and further mediated by CRABP proteins present in the ventricular and atrial myocytes. The presence of RALDH2 enzyme detected within the epicardium in this study as well as in previous publications (Moss et al., 1998; Berggren et al., 1999; Xavier-Neto et al., 2000; Berggren et al., 2001; Hoover et al., 2008) combined with the presence of cells stained positively for RALDH2, which migrate from the epicardium towards myocardium, could also support these claims.

RALDH2 has been characterized as the major RA synthesizing enzyme in the embryo (Zhao et al., 1996; Berggren et al., 1999; Vermot et al., 2006). We were interested whether exogenous RA would alter the level of Raldh2 gene expression. We observed a down-regulation of Raldh 2 mRNA in RA-treated hearts at $9 \mathrm{dpc}$, but at 10 and $11 \mathrm{dpc}$ this gene was up-regulated. Susceptibility of this enzyme to regulation by its own product has been proven in P19 embryonal carcinoma cells (Zhao et al., 1996). Similarly Napoli (1999) classifies Raldh2 as an RA-responsive gene, noticing that its response to RA might be tissue specific. A response of RALDH2 to RA has also been detected in some structures of the murine embryo, 12 and $27 \mathrm{~h}$ after maternal RA treatment, which was administered precisely at $8.5 \mathrm{dpc}$ (Neiderreither et al., 1997b). Regardless of the exact mechanisms responsible for the fact that the reaction of RALDH2 to exogenous RA varied in time, these results clearly show that a single dose of retinoic acid administered at the critical time of cardiogenesis $(8.5 \mathrm{dpc})$ may affect production of endogenous RA within the developing heart.
Furthermore, immunohistochemical staining with antiRALDH2 antibodies following RA treatment reveals additional signal, although weak, in the myocardium of the OT and the ventricles at $10 \mathrm{dpc}$. This extopic expression of RALDH2 does not, however, correlate with the level of total RALDH2 protein expression at that time (Fig. 4C).

A strong distinctive pattern of RALDH2 labeling is also present in the distal portion of the outflow tract as well as in surrounding tissues. These areas are known to be in spatial contact with the NCCs immediately before the immigration of these cells into the outflow tract. It is thought that RALDH2 is not expressed in the migrating CNCCs (Niederreither et al., 1997a; Berggren et al., 1999). However, it is believed that for successful migration of these cells, a specific pattern of RA must be provided throughout their migratory pathways (Niederreither et al., 1997a; Berggren et al., 1999). It is therefore possible that aberrant induction of RALDH2 expression in the OT of 10-dpc hearts could lead to reduced migration of NCCs into this structure, and in consequence to the OT septation defects persistent in this model (Yasui et al., 1995; 1997; 1999; Nakajima et al., 1996; 1997). As stated above, the gradient of CRABP II affected by $\mathrm{RA}$ at $11 \mathrm{dpc}$ seems to be consistent with this hypothesis. However, further studies are required to determine whether in this case the abolished gradient of CRABP II reflects specifically the reduction in the number of migrating NCCs. Alternatively, both changes in spatial expression of CRABP II and RALDH2 may reflect the increased sensitivity of the affected heart areas to excess RA signaling.

Regardless of the specific mechanism it is evident that expression of both Crabp I and II as well as Raldh2 genes (mRNA levels) is responsive to RA excess administered during the heart looping stage.

Based on our findings we cannot deduce what are the exact regulatory mechanisms of CRABPs' action in the RA signaling network, however, RA-induced regulation of mRNA and protein levels of both CRABPs at the stages of cardiac loop formation SHF cells addition to the outflow tract and subsequent OT alignment, suggests that these proteins may be involved in these major developing processes of the heart and may mediate RA signaling.

\section{Acknowledgements}

This work was partially supported by the Ministry of Science and Higher Education grants (2 P05A 11128 , $2701 / \mathrm{B} / \mathrm{P} 01 / 2010 / 39)$ and by internal funds of the Medical University of Warsaw. The Faculty of Biochemistry, Biophysics and Biotechnology of the Jagiellonian University is a beneficiary of the structural funds from the European Union (grant No: POIG.02.01.00-12064/08 - Molecular biotechnology for health).

The authors are grateful to Anna Podbielska for her excellent technical help and to Peter McCaffery for the kind gift of anti-RALDH2 antibodies. Alicja Jozkowicz is an International Senior Research Fellow of the Welcome Trust.

\section{REFERENCES}

Aström A, Tavakkol A, Pettersson U, Cromie M, Elder JT, Voorhees JJ (1991) Molecular cloning of two human cellular retinoic acid-binding proteins (CRABP). Retinoic acid-induced expression of 
CRABP-II but not CRABP-I in adult human skin in vivo and in skin fibroblasts in vitro. J Biol Chem 266: 17662-17666.

Berggren K, McCaffery P, Dräger U, Forehand CJ (1999) Differential distribution of retinoic acid synthesis in the chicken embryo as determined by immunolocalization of the retinoic acid synthetic enzyme, RALDH-2. Dev Biol 210: 288-304.

Berggren K, Ezerman EB, McCaffery P, Forehand CJ (2001) Expression and regulation of the retinoic acid synthetic enzyme RALDH-2 in the embryonic chicken wing. Dev Dyn 222: 1-16.

Bernlohr DA, Simpson MA, Hertzel AV, Banaszak LJ (1997) Intracellular lipid-binding proteins and their genes. Annu Rev Nutr 17: $277-303$.

Bouman HGA, Broekhuizen MLA, Baasten AMJ, Gittenberger-de Groot AC, Wenink ACG (1995) Spectrum of looping disturbances in stage 34 chicken hearts after retinoic acid treatment. Anat Rec 243: 101-108.

Boylan JF, Gudas LJ (1992) The level of CRABP-I expression influences the amounts and types of all-trans-retinoic acid metabolites in F9 teratocarcinoma stem cells. J Biol Chem 267: 21486-21491.

Bucco RA, Zheng WL, Wardlaw SA, Davis JT, Sierra-Rivera E, Osteen KG, Melner MH, Kakkad BP, Ong DE (1996) Regulation and localization of cellular retinol-binding protein, retinol-binding protein, cellular retinoic acid-binding protein (CRABP) and CRABP II in the uterus of the pseudopregnant rat. Endocrinology 137: 3111-3122.

Buckingham M, Meilhac S, Zaffran S (2005) Building the mammalian heart from two sources of myocardial cells. Nat Rev Genet. 6: $826-835$.

Collop AH, Broomfield JAS, Chandratana RAS, Yong Z, Deimling SJ, Kolker SJ, Weeks DL, Drysdale TA (2006) Retinoic acid signaling is essential for formation of the heart tube in Xenopus. Dev Biol 291: 96-109.

Dekker EJ, Vaessen MJ, van den Berg C, Timmermans A, Godsave S, Holling T, Nieuwkoop P, Geurts van Kessel A, Durston A (1994) Overexpression of a cellular retinoic acid binding protein $(x C R A B P)$ causes anteroposterior defects in developing Xenopus embryos. Development 120: 973-985.

Delva L, Bastie Jean-Nöel, Rochette-Egly C, Krad'ba R, Balitrand N, Despouy G, Chambon P, Chomienne C (1999) Physical and functional interactions between cellular retinoic acid binding protein II and the retinoic acid-dependent nuclear complex. Mol Cell Biol 19: $7158-7167$.

Dingle JT, Fell HB, Goodman DS (1972) The effect of retinol and of retinol-binding protein on embryonic skeletal tissue in organ culture. J Cell Sci 11: 393-402.

Dong D, Ruuska SE, Levinthal DJ, Noy N (1999) Distinct roles for cellular retinoic acid-binding proteins I and II in regulating signaling by retinoic acid. J Biol Chem 274: 23695-23698.

Durand B, Saunders M, Leroy P, Leid M, Chambon P (1992) All-trans and 9-cis retinoic acid induction of CRABP II transcription is mediated by RAR-RXR heterodimers bound to DR1 and DR2 repeated motifs. Cell 71: 73-85.

Gaub MP, Lutz Y, Ghyselinck NB, Scheuer I, Pfister V, Chambon P, Rochette-Egly C (1998) Nuclear detection of cellular retinoic acid binding proteins I and II with new antibodies. J Histochem Cytochem 46: 1103-1111.

Giguére V, Lyn S, Yip P, Siu CH, Amin S (1990) Molecular cloning of cDNA encoding a second cellular retinoic acid-binding protein. Proc Natl Acad Sci USA 87: 6233-6237.

Hildreth V, Webb S, Bradshaw L, Brown NA, Anderson RH, Henderson DJ (2008) Cells migrating from the neural crest contribute to the innervation of the venous pole of the heart. $J$ Anat 212: 1-11.

Hoover LL, Burton EG, Brooks BA, Kubalak SW (2008) The expanding role for retinoid signaling in heart development. Sci World J 8: 194-211.

Hutson MR, Zhang P, Stadt HA, Sato AK, Li YX, Burch J, Creazzo TL, Kirby ML (2006) Cardiac arterial pole alignment is sensitive to FGF8 signaling in the pharynx. Dev Biol 295: 486-497.

Ilagan R, Abu-Issa R, Brown D, Yang YP, Jiao K, Schwartz RJ, Klingensmith J, Meyers EN (2006) Fgf8 is required for anterior heart field development. Development 133: 2435-2445.

Jiang X, Rowitch DH, Soriano P, McMahon AP, Sucov HM (2000). Fate of the mammalian cardiac neural crest. Development 127: 16071616.

Kalter H, Warkany J (1961) Experimental production of congenital malformations in strains of inbred mice by maternal treatment with hypervitaminosis A. Am J Pathol 38: 1-21.

Kang I-O, Sucov HM (2005) Convergent proliferative response and divergent morphogenic pathways induced by epicardial and endocardial signaling in fetal heart development. Mech Dev 122: 57-65.

Kastner P, Grondona JM, Mark M, Gansmuller A, LeMeur M, Decimo D, Vonesh JL, Dolle P, Chambon P (1994) Genetical analysis of RXRa developmental function; convergence of RXR and RAR signaling pathways in heart and eye morphogenesis. Cell 78: 987-1003.

Kelly RG, Brown NA, Buckingham ME (2001) The arterial pole of the mouse heart forms from Fgf10-expressing cells in pharyngeal mesoderm. Dev Cell 1: 435-440.
Kleinjan DA, Dekker S, Vaessen MJ, Grosveld FG (1997) Cloning and regulation of the CRABP-I gene during mouse embryogenesis. Mech Dev 67: 157-69.

Kleinjan DA, Dekker S, Guy JA, Grosveld FG (1998) Cloning and sequencing of the CRABP-I locus from chicken and pufferfish: analysis of the promoter regions in transgenic mice. Transgenic Res 7: 85-94.

Laemmli UK (1970) Cleavage of structural proteins during the assembly of the head of bacteriophage $\mathrm{T}_{4}$. Nature 227: 680-685.

Lammer EJ, Chen DT, Hoar RM, Agnish ND, Benke PJ, Braun JT, Curry CJ, Fernhoff PM, Grix AW Jr, Lott IT (1985) Retinoic acid embryopathy. $N$ Engl J Med 313: 837-841.

Lampron C, Rochette-Egly C, Gorry P, Dolle P, Mark M, Lufkin T, Le Meur M, Chambon P (1995) Mice deficient in cellular retinoic acid binding protein II (CRABP II) or in both CRABPI and CRABPII are essentially normal. Development 121: 539-548.

Lavine KJ, Yu K, White AC, Zhang X, Smith C, Partanen J, Ornitz DM (2005) Endocardial and epicardial derived FGF signals regulate myocardial proliferation and differentiation in vivo. Dev Cell 8: 85-95.

Lee YM, Kim JS, Han SY, Park KL, Jang SJ, Seo JW (1998) Abnormal ventricular looping and abnormal laterality of the atrial chambers are the main morphogenetic mechanisms of the cardiac lesions in cultured rat embryos treated with retinoic acid. J Korean Med Sci 13: $117-122$.

Leonard L, Horton C, Maden M, Pizzey JA (1995) Anteriorization of CRABP-I expression by retinoic acid in the developing mouse central nervous system and its relationship to teratogenesis. Dev Biol 168: $514-528$.

Lin S-C, Dollé P, Ryckebüsch L, Noseda M, Zaffran S, Schneider MD, Niederreither K (2010) Endogenous retinoic acid regulates cardiac progenitor differentiation. Proc Natl Acad Sci USA 107: 9234-9239.

Lyn S, Giguére V (1994) Localization of CRABP I and CRABP II mRNA in the early mouse embryo by whole mount in situ hybridization: implications for teratogenesis and neural development. Dev Dyn 199: 280-291.

Maden M (1994) Distribution of cellular retinoic acid binding proteins I and II in the chick embryo and their relationship to teratogenesis. Teratology 50: 294-301.

Maden M, Ong DE, Summerbell D, Chytil F (1988) Spatial distribution of cellular protein binding to retinoic acid in the chick limb bud. Nature 335: 733-735.

Maden M, Ong DE, Chytil F (1990) Retinoid-binding protein distribution in the developing mammalian nervous system. Development 109: 75-80.

Maden M, Hunt P, Eriksson U, Kuroiwa A, Krumlauf R, Summerbell D (1991) Retinoic acid-binding protein, rhombomeres and the neural crest. Development 111: 35-44.

McCaffery P, Dräger UC (2000) Regulation of retinoic acid signaling in the embryonic nervous system: a master differentiation factor. $C y$ tokine Growth Factor Rev 11: 233-249.

Mjaatvedt CH, Nakaoka T, Moreno-Rodriguez R, Norris RA, Kern MJ, Eisenberg CA, Turner D, Markwald RR (2001) The outflow tract of the heart is recruited from a novel heart-forming field. Dev Biol 238: 97-109.

Moss JB, Xavier-Neto J, Shapiro MD, Nayeem SM, McCaffery P, Dräger UC, Rosenthal N (1998) Dynamic patterns of retinoic acid synthesis and response in the developing mammalian heart. Dev Biol 199: $55-71$.

Nakajima Y, Hiruma T, Nakazawa M, Morishima M (1996) Hypoplasia of cushion ridges in the proximal outflow tract elicits formation of a right ventricle-to-aortic route in retinoid acid-induced complete transposition of the great arteries in the mouse: scanning electron microscopic observations of corrosion cast models. Anat $\operatorname{Rec} 245$ : 76-82.

Nakajima Y, Morishima M, Nakazawa M, Momma K, Nakamura H (1997) Distribution of fibronectin, type I collagen, type IV collagen and laminin in the cardiac jelly of the mouse embryonic heart with retinoic acid-induced complete transposition of the great arteries. Anat Rec 249: 478-485.

Napoli JL (1999) Interactions of retinoid binding proteins and enzymes in retinoid metabolism. Biochem Biophys Acta 1440: 139-162.

Niederreither K, Vermot J, Messaddeq N, Schuhbaur B, Chambon P, Dollé P (1997a) Embryonic retinoic acid synthesis is essential for heart morphogenesis in the mouse. Development 128: 1019-1031.

Niederreither K, McCaffery P, Dräger UC, Chambon P, Dollč P (1997b) Restricted expression and retinoic acid-induced downregulation of the retinaldehyde dehydrogenase type 2 (RALDH-2) gene during mouse development. Mech Dev 62: 67-78.

Niederreither K, Subbarayan V, Dollé P, Chambon P (1999) Embryonic retinoic acid synthesis is essential for early mouse post-implantation development. Nat Genet. 21: 444-448.

Ong DE, Newcomer ME, Chytil F (1994) Cellular retinoid-binding proteins. In The Retinoids: Biology, Chemistry and Medicine. Sporn MB, Roberts AB, Goodman DS, eds, 2nd edn, pp 283-317. Raven Press, New York. 
Park EJ, Ogden LA, Talbot A, Evans S, Cai CL, Black BL, Frank DU, Moon AM (2006) Required, tissue-specific roles for Fgf8 in outflow tract formation and remodeling. Development 133: 2419-2433.

Perez-Castro AV, Toth-Rogler LE, Wei LN, Nguyen-Huu MC (1989) Spatial and temporal pattern of expression of the cellular retinoic acid-binding protein and the cellular retinol-binding protein during mouse embryogenesis. Proc Natl Acad Sci USA 86: 8813-8817.

Poelmann RE, Gittenberger-de Groot AC (1999) A Subpopulation of apoptosis-prone cardiac neural crest cells targets to the venous pole: multiple functions in heart development? Dev Biol 207: 271-286.

Rochais F, Mesbach K, Kelly RG (2009) Signaling pathways controlling second heart field development. Circ Res 104: 933-942.

Rosa FW, Wilk AL, Kelsey FO (1986) Teratogen update: vitamin A congeners. Teratology 33: 355-364.

Ross SA, McCaffery PJ, Dräger U, De Luca LM (2000) Retinoids in embryonal development. Physiol Rev 80: 1021-1054.

Ruberte E, Dolle P, Krust A, Zelent A, Morrisss-Kay GM, Chambon $P$ (1990) Specific spatial and temporal distribution of retinoic acid receptor gamma transcripts during mouse embryogenesis. Development 108: 213-222.

Ruberte E, Dolle P, Chambon P, Morrisss-Kay GM (1991) Retinoic acid receptors and cellular retinoid binding proteins. II. Their differential pattern of transcription during early morphogenesis in mouse embryos. Development 111: 45-60.

Ruberte E, Friederich V, Morriss-Kay GM, Chambon P (1992) Differential distribution patterns of CRABP I and CRABP II transcripts during mouse embryogenesis. Development 115: 973-987.

Ryckebusch L, Wang Z, Bertrand N, Lin SCC, Chi X, Schwartz R, Zaffran S, Neiderreither K (2008) Retinoic acid deficiency alters second heart field formation. Proc Natl Acad Sci USA 105: 29132918.

Sinning AR (1998) Role of vitamin A in the formation of congenital heart defects Anat Rec (New Anat) 253: 147-153.

Sirbu IO, Zhao X, Duester G (2008) Retinoic acid controls heart anteroposterior patterning by downregulating Isla1 through the Fgf8 pathway. Dev Dyn 237: 1627-1635.

Sucov HM, Dyson E, Gumeringer CL, Price J, Chien KR, Evans RM (1994) RXRa mutant mice establish a genetic basis for vitamin A signaling in heart morphogenesis. Genes Dev 8: 1007-1018.

Theodosiou M, Laudet V, Schubert M (2010) From carrot to clinic: on overview of the retinoic acid signaling pathway. Cell Mol Life Sci 67: 1423-1445.

Vaessen M-J, Meijers JHC, Bootsma D, van Kessel AG (1990) The cellular retinoic-acid-binding protein is expressed in tissues associated with retinoic-acid-induced malformations. Differentiation 110: $371-378$.

Vermot J, Messaddeq N, Neiderreither K, Dierich A, Dollé P (2006) Rescue of morphogenetic defects and of retinoic acid signaling in retinaldehyde dehydrogenase 2 (Raldh2) mouse mutants by chimerism with wild-type cells. Differentiation 74: 661-668.

Waldo KL, Hutson MR, Zdanowicz M, Stadt HA, Zdanowicz J, Kirby ML (2005) Cardiac neural crest is necessary for normal addition of the myocardium to the arterial pole from the secondary heart field. Dev Biol 281: 66-77.

Wang Z, Zhai W, Richardson JA, Olson EN, Meneses JJ, Firpo MT, Kang C, Skarnes WC, Tjian R (2004) Polybromo protein BAF 180 functions in mammalian cardiac chamber maturation. Genes Dev 18: 3106-3116.

Waxman JS, Keegan BR, Roberts RW, Poss KD, Yelon D (2008) Hoxb5b acts downstream of retinoic acid signaling in the forelimb field to restrict heart field potential in zebrafish. Dev Cell 15: 923934.

Williams SS, Mear JP, Liang HC, Potter SS, Aronow BJ, Colbert MC (2004) Large-scale reprogramming of cranial neural crest gene expression by retinoic acid exposure. Physiol Genomics 19: 184-197.

Wilson JG, Roth CB, Warkany J (1953) An analysis of the syndrome of malformations included by maternal vitamin A deficiency. Effects of restoration of vitamin $\mathrm{A}$ at various times during gestation. Am J Anat 92: 189-217.

Xavier-Neto J, Shapiro MD, Houghton L, Rosenthal N (2000) Sequential programs of retinoic acid synthesis in the myocardial and epicardial layers of the developing avian heart. Dev Biol 219: 129-141.

Yasui H, Nakazawa M, Morishima M, Mivagawa-Tomita S, Momma K (1995) Congenital heart disease: morphological observations on the pathogenic process of transposition of the great arteries induced by retinoic acid in mice. Circulation 91: 2478-2486.

Yasui H, Nakazawa M, Morishima M, Ando M, Takao A, Aikawa E (1997) Cardiac outflow tract septation process in the mouse model of transposition of the great arteries. Teratology 55: 353-363.

Yasui H, Morishima M, Nakazawa M, Ando M, Aikawa E (1999) Developmental spectrum of cardiac outflow tract anomalies encompassing transposition of the great arteries and dextroposition of the aorta: pathogenic effect of extrinsic retinoic acid in the mouse embryo. Anat Rec 254: 253-260.

Yelbuz TM, Waldo KL, Kumiski DH, Stadt HA, Wolfe RR, Leatherbury L, Kirby ML (2002) Shortened outflow tract leads to altered cardiac looping after neural crest ablation. Circulation 106: 504-510.

Zhao D, McCaffery P, Ivins KJ, Neve RL, Hogan P, Chin WW, Dräger UC (1996) Molecular identification of a major retinoic-acid synthesizing enzyme: a retinaldehyde-specific dehydrogenase. Eur J Biochem 204: 15-22.

Zhelyaznik N, Schrage K, McCaffery P, Mey J (2003) Activation of retinoic acid signaling after sciatic nerve injury: up-regulation of cellular retinoid binding proteins. Eur J Neuroscience 18: 1033-1040. 